\title{
Comparative anthelmintic activity of Aegle marmelos Linn leaves and pulp
}

\author{
Kishan Singh*, Krishn Kumar Agrawal, Jeetendra Kumar Gupta \\ Institute of Pharmaceutical Research, GLA University Mathura, (U.P.)-281406
}

\begin{abstract}
In the present work, experiments were conducted to evaluate the possible anthelmintic effects of different extracts of Aegle marmelos leaves and pulp on Indian earthworm (Pheretima posthuma) at $20 \mathrm{mg} / \mathrm{ml}$ concentration. Results were expressed in terms of time for paralysis and time for death of worms. Piperazine citrate, pyrantal pamoate and albendazole were used as a standards and DMSO in distill water as a control group. The result revealed that leaves extracts of Aegle marmelos has better activity that pulp extracts but not better than the standards.
\end{abstract}

Keywords: Anthelmintic, Albendazole, Aegle marmelos, pyrantel pamoate

\section{INTRODUCTION}

Helminthes parasite infections are global problems with serious social and economic repercussions in the Third World countries. Parasitic helminths affect animals and man and animals than any single group of parasites, causing considerable hardship and stunted growth. Most diseases caused by helminthes are of a chronic, debilitating nature; they probably cause more morbidity and greater economic and social deprivation among humans The diseases affect the health status of a large fraction of the human population as well as animals.1 Herbal drugs have been in use since ancient times for the treatment of parasitic disease in human and could be of value in preventing the development of resistance.2, $3 \mathrm{~A}$ tree has unarmed branches and glabrous pedicles in pairs. The fruits are used as laxative and refrigerant. Prunes are often added to cathartic decoctions, improving their flavor and promoting their effect. They are also given in combination with other drugs in leucorrhoea and irregular menstruation. Literature survey revealed that plant extract has yet not been screened for anthelmintic activity. Therefore, the objective of this work was to assess the anthelmintic activity of Aegle marmelos leaves.

\section{Material and Methods}

Drugs and chemicals: Piperazine citrate, albendazole and pyrantal pamoate were used as standard drugs.

Chemicals: Petroleum ether (60-80), Ethanol, Di methyl sulfoxide (DMSO) and sodium chloride were used in various part of experiment.

Collection of plant material: Leaves of Aegle marmelos were collected from local area of Mathura and authenticated by Birbal Sahani Institute of Palaeobotony, Lucknow, Uttar Pradesh. (Voucher specimen no.13371/2011). Collected leaves were washed and dried at room temperature. After complete drying, leaves were powdered and passed through a sieve and stored in air tight container.

Preparation of extracts: The Aegle marmelos were collected from Mathura (Uttar Pradesh) and dried in shade and coarsely powdered. It was than passed through the sieve no. 20. A weighted quantity $(460 \mathrm{~g})$ of the powder drug was extracted with petroleum ether $\left(60-80^{\circ} \mathrm{C}\right)$ using soxhlet extractor. Defatted drug was subjected to ethanolic extraction and extract was dried by distilling off the solvent and then dried in desiccator. The marc collected after ethanolic extraction was subjected to aqueous extraction by maceration process for seven days consecutively and then extract was dried by evaporating the water and stored for further activity.

Experimental worms: The earthworms of 3-5 cm in length and $0.1-0.2 \mathrm{~cm}$ in width were used for all the experimental protocol due to its anatomical and physiological resemblance with the intestinal roundworm parasites of human beings.5, 6 
Anthelmintic screening: The anthelmintic activity was carried out as per the protocol of Ajaiyeoba et al.7 four groups of approximately equal size Indian earthworms consisting of six earthworms in each group were used for the study. Each group was treated as following:

Group-I - Vehicle (DMSO in Distill water)

Group-II - Piperazine citrate, Albendazole, Pyrantel pamoate $(20 \mathrm{mg} / \mathrm{ml})$

Group-III- Aqueous extract of leaves and pulp $(20 \mathrm{mg} / \mathrm{ml})$

Group-IV- Ethanol extract of leaves and pulp $(20 \mathrm{mg} / \mathrm{ml}$.)

Observations were made for the time taken to paralysis and death of individual worms. Time for paralysis was noted when no movement of any sort could be observed except when the worms were shaken vigorously. Death was concluded when the worms lost their motility followed with fading away of their body colors. 8,9

\section{Observation table:}

Table 1: Anthelmintic Activity of ethanol extracts of Aegle marmelos against Earthworm

\begin{tabular}{|c|c|c|c|c|}
\hline \multirow{2}{*}{ Groups } & \multirow{2}{*}{ Treatment } & \multirow{2}{*}{ Concentration } & \multicolumn{2}{|c|}{ Time taken to paralysis and death of worms } \\
\hline & & & Paralysis time (Min.) & Death Time (Min.) \\
\hline Control & Drugless & $\begin{array}{l}5 \% \text { DMSO in Distill } \\
\text { water }\end{array}$ & 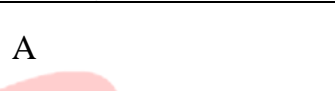 & 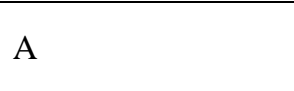 \\
\hline \multirow{6}{*}{ Test } & \multicolumn{4}{|l|}{ Aegle marmelos (Pulp) } \\
\hline & a. Aqueous & $20 \mathrm{mg} / \mathrm{ml}$ & $32.38 \pm 1.007$ & $59.03 \pm 0.3295$ \\
\hline & b. Ethanolic & $20 \mathrm{mg} / \mathrm{ml}$ & $33.75 \pm 0.8167$ & $54.16 \pm 0.5757$ \\
\hline & $\begin{array}{l}\begin{array}{l}\text { Aegle } \\
\text { (Leaves) }\end{array} \\
\end{array}$ & & & \\
\hline & c. Aqueous & $20 \mathrm{mg} / \mathrm{ml}$ & $26.98 \pm 0.7411$ & $51.43 \pm 1.182$ \\
\hline & d. Ethanolic & $20 \mathrm{mg} / \mathrm{ml} S \mathrm{~S}$ & $27.67 \pm 0.4875$ & $55.07 \pm 1.307$ \\
\hline \multirow{3}{*}{ Standard } & Albendazole & $20 \mathrm{mg} / \mathrm{ml}$ & $28.76 \pm 0.3812$ & $50.39 \pm 0.8105$ \\
\hline & Piperazine Citrate & $20 \mathrm{mg} / \mathrm{ml}$ & $7.81 \pm 0.1661$ & A \\
\hline & Pyrantel pamoate & $20 \mathrm{mg} / \mathrm{ml}$ & $21.60 \pm 0.4647$ & $64.58 \pm 1.948$ \\
\hline
\end{tabular}

Results are expressed as Mean \pm SEM, $n=6$ in each group

$\mathrm{A}=$ absent of activity,

\section{Result and Discussion}

In this anthelmintic study both the extracts (Aqueous and Ethanolic) of Aegle marmelos produce paralysis as well as death of the worms. As shown in table2, aqueous and ethanolic extract exhibited anthelmintic activity as in standards (i.e. Piperazine citrate, Albendazole and Pyrantel pamoate). Although, Piperazine citrate caused only paralysis not death of the worms. Furthermore the anthelmintic effect of aqueous and ethanolic extract of Aegle marmelos was comparable with the standard drugs, although it caused paralysis as well as death of worms similar to albendazole and Pyrantel pamoate.

\section{Conclusion}

It can be concluded that the ethanolic and aqueous extract of Aegle marmelos leaves have profound anthelmintic activity against tested worms but not better than standards. Further in future researches will also being carried out in our department to establish the prescribed mechanism of action and to identify phytochemical moiety which is responsible for this activity.

\section{ACKNOWLEDGMENT}


Authors are thankful to Prof .Pradeep Mishra Director, Institute of Pharmaceutical Research, GLA University for providing the necessary facilities and support to carry out this work.

\section{REFERENCE}

1. Daniel Vivek, Daniela Kratika, Goyal Swapnil, Parihar S Mahendra and Singh Mangal. (2010). Synthesis and Invitro Anthelmintic Activity of Some 4-aminophenol Derivatives. International Journal of Pharmaceutical Research, Vol 2, (2): 21-24.

2. Chopra RN, Naver SC, ChopraIC. (1956).Glossary of Indian Medicinal Plants. New Delhi, CSIR 160.

3. Hammond DA, Fielding D, Bishop SC. (1997). Prospects for plant anthelmintic in tropical veterinary medicine. Vet Res Comm, 21: 213-228.

4. Kirtikar KR, Basu BD. (2005) .Indian Medicinal Plants .vol.2.International book distr., page no.

5. Thorn GW,Admas RD,Braunwald E.Isselbacher KJ,Petersdorf RG.(1977).Harrisons Principles of internal Medicine, McGraw Hill Co, New York.

6. Vigar Z. (1984).Atlas of medical parasitology, 2nd Edn. P.G.Publishing Housing, Singapore.

7. Ajaiyeoba EO, Onocha PA and Olarenwaju OT. (2001).Invitro anthelmintic properties of buchholzia coriaceae and Gynandropsis gyanendra extract .pharm boil. 39:217-20

8. Vagdevi HM, Latha KP, Vaidya VP, Vijayakumar M and Pai KS. (2001). Synthesis and Pharmacological screening of some novel naphtha (2, 1-b) Furo-pyrazolines, isoxazoles and isoxazolines, Indi. J. Pharma. Sci, 63: 286-291.

9. Boltan S:in pharmaceutical Statistic-practical and Clinical Applications.(1997).new York Marcel Dekker,67-78

10. Thompson DP, Geary TG. (1995). The structure and function of helminths surfaces in Biochemistry and Molecular Biology of parasites 1st ed. Academic press, New York, pp.203-232. 